\title{
Stress and Burnout among Nurses Working in Menoufia University Hospitals
}

\author{
El Dalatony MMi ${ }^{*}$, Hathout $\mathrm{HM}^{2}$ and Allam HK${ }^{1}$ \\ ${ }^{1}$ Industrial Medicine and Occupational Health, Public Health and Community \\ Medicine Department, Menoufia University, Egypt \\ ${ }^{2}$ Community Medicine and Environmental Health, Public Health and Community \\ Medicine Department, Menoufia University, Egypt
}

\section{Research Article \\ Volume 3 Issue 3}

Received Date: April 30, 2019

Published Date: May 14, 2019

DOI: $10.23880 /$ eoij-16000207

*Corresponding author: Mervat Mohamed El Dalatony, MD, Industrial Medicine and Occupational Health, Public Health and Community Medicine Department, Menoufia University, Egypt; Email: mervat.moh.abd@gmail.com

\section{Abstract}

Background: Every work environment, especially within a hospital setup, needs to be conducive, friendly and stress-free to promote quality care and wellbeing of health care workers whose job demands are increasing day by day. As healthcare providers are exposed to high stress degrees during their work, so we conducted the present work aiming to study stress and burnout among nurses working in Menoufia University hospitals.

Methods: A cross-sectional study involved 158 nurses in different departments in Menoufia University Hospitals. Tools used in this study were data collection forms including different forms including sociodemographic factors, work-related factors, Job satisfaction questions, stress and Burnout questions, Burnout prevention Survey. Data analyzed using IBM SPSS Statistics for Windows version 21.0.

Results: Significant factors associated with stress among nurses are gender, educational level, working department, Job satisfaction, and working hours/ week. The binomial logistic analysis found that education, working hours/ week are independent significant factors associated with stress among the study group. The only significant factor associated with burnout prevention and the ability to cope with stress is working years.

Conclusion: A comprehensive review of working hours, responsibilities and distribution of work are strongly recommended. Together with multiple interventions to help staff to cope with stress through counseling, motivation, redistribution of work, reducing working hours, and recruitment of new staff.

Keywords: Burnout; Healthcare Workers; Stress at Work; Occupational; Stress Management 


\section{Ergonomics International Journal}

\section{Introduction}

The National Institute for Occupational Safety and Health (NIOSH) defines occupational stress as "the harmful physical and emotional responses that occur when the requirements of the job do not match the capabilities, resources, or needs of the worker [1].

Nowadays, more and more employees experience stress at work. This stress may result from work overload, high demands, poor work conditions, longer working hours, lack of control (autonomy) or lack of social support and rewards. There is substantial evidence that stress can lead to various negative consequences for individuals, including somatic diseases, mental health disorders or feeling of exhaustion. The impact on organizations is reflected in increased accident rates or poorer production performance, premature retirement, and sickness absence [2].

Burnout syndrome (BOS) has been defined as the experience of long-term exhaustion and diminished interest, usually in the work context [3]. So, burnout is considered as the clinical manifestation of occupational stress. Burnout may have significant impacts on individuals such as loss of job, family relations, psychological disorders, and addictive behavior. In terms of organizational outcome; job burnout causes absenteeism, inefficiency in innovative capabilities and loss of productivity [4]. Burnout syndrome (BOS) may affect workers of any kind; however, high-stress jobs can lead to more BOS than lower stress jobs [5].

The Study findings of Halder S, et al. [6] support a common perception regarding high stress in certain work professionals, like those in the Armed forces, police, high vigilance duties in railways and power-grids to name a few Information technology professionals, Medical representatives and Insurance agents too, who always have difficult business targets to meet are considered to be another stressed group of work professionals. Health care professionals too are not immune to stress. While doctors are perceived as an elite group of professionals with relatively better pay packages and job securities, the same could not be true for other health care professionals.

Centers for Diseases Prevention and Control [1] stated that the most common stressors in health care settings include inadequate staffing levels, long work hours, shift work, role ambiguity and exposure to infectious and hazardous substances. "Those work stressors usually vary depending on the task performed".

El Dalatony MM, et al. Stress and Burnout among Nurses Working in Menoufia University Hospitals. Ergonomics Int J 2019, 3(3): 000207.
However, American Psychological Association [7] suggests a range of ways that a working environment can be changed to help reduce stress: workloads in the same line as a worker's capabilities and resources, clearly defined worker's roles and responsibilities, communication, and opportunities for social interaction among workers.

Moreover, healthcare professionals, who experience stress or have symptoms of burnout have a possibility to help themselves by using psychological methods and coping techniques, such as meditation, relaxation, and arttherapy [8].

\section{Work Objective}

Study stress and burnout among nurses working in different departments of Menoufia University hospitals and possible associated factors.

\section{Subjects \& Method}

\section{Type of Study}

A cross-sectional study involved nurses working in Menoufia University Hospitals during the period from September- December 2018. Departments involved (Intensive care units including adult, pediatric, and neonatal ICUs), Medical Departments including (internal medicine, pediatric, hepatology departments), Surgical departments including (orthopedics-general surgeryophthalmology \& ENT). All registered nurses in Menoufia University Hospitals who were practicing during the data collection period of the study were invited to participate. Those who had duration of employment of less than one year were excluded.

The number of eligible nurses for the study was 209. The purpose of the study was explained to the nurses to get their approval. The number of participants who agreed to share in the study (158) with a response rate of $75.59 \%$.

\section{Study Tools}

Data were collected using a self-administered questionnaire composed of 4 sections;

Section 1: Sociodemographic and work characteristics: including age, marital status, and level of education, working hours per week, working years, and occupation.

Section 2: Job satisfaction survey: A survey which includes (30) questions related to nature of work, 


\section{Ergonomics International Journal}

interpersonal relationship, pay and allowances, working environment, training, management policies, personal growth, and career development.

Each question takes (2) if a positive attitude and (0) if a negative attitude. The total score is (60). 3 categories will be identified based on nurse's response [9]:

$>$ 45----- Satisfied,

$>>30$ - 45 Average,

$><30$ dissatisfied

\section{Section 3: Stress and burnout questionnaire}

This brief valid inventory has been designed to discover the warning signals of excessive stress based on participant own evaluation of his life over the last 3-6 months [10]. The tool includes (25) questions, each item were answered on a 3-point Likert scale

Score 0 - For experiencing this only occasionally

Score 1 - This is true quite frequently (weekly)

Score 2 - This true often (usually daily)

The total score is (50) with a high score indicating a high level of stress and burnout.

\section{Section 4: Burnout Prevention Assessment}

Include (23) statements reflecting important ways that participant use to prevent burnout [10]

The tool is translated into Arabic. Each question has a different score scale. The participants select the best answer based on the frequency of preventive measures he used to cope with stress.

The total score for this tool $=100$

Based on the total score, the participant response was categorized as follows:-

1. Over $60 \longrightarrow$ coping well with stress (a wide range of preventive measures are adopted by a participant to cope with stress and burnout).

2. Over $40 \longrightarrow$ coping with stress to some extent (some preventive measures are adopted by a participant to cope with stress and burnout).

3. $\leq 40 \longrightarrow$ unable to cope with stress (limited range of preventive measures are adopted by a participant to cope with stress and burnout).

\section{Pilot Study}

The tools were translated into Arabic and applied to a group of nurses to study feasibility, time taking to fill the forms before conducting a full-scale study.

The average time taken to fill the form was 10-15 minutes which was considered acceptable.

\section{Statistical Analysis}

The collected data were coded, typed onto computer files, tabulated and analyzed using Statistical Package for Social Sciences (SPSS) program version 21.

Descriptive statistics including frequency, percentages, arithmetic mean (X) and standard deviation (SD) were used to describe the study population.

The relationship between mean stress score, demographic factors, and work-related factors were determined used independent t-test in case of a dichotomous variable, and One-way analysis of variance (ANOVA) is used to determine whether there are any statistically significant differences between the means of three or more independent (unrelated) groups.

Correlation is used to study the relationship between two quantitative, continuous variables, for example, working hours, working years, and stress and burnout score. Pearson's correlation coefficient ( $\mathrm{r}$ ) is calculated to measure the strength of association between the two variables.

The binomial logistic analysis is used for burnout using independent significant variables in the univariate analysis. The significance level was set at $\mathrm{P}<0.05$. All statistical analyses were conducted using IBM SPSS Statistics for Windows version 21.0.

\section{Ethical Clearance}

Objectives of the study, procedures, types of information to be obtained, and publication were explained to participants. Informed consent was obtained from each participant at the beginning of the study. Collected data were confidentially kept. 


\section{Results}

Table 1: Relation between stress and burnout score and sociodemographic and working factors.

\begin{tabular}{|c|c|c|c|c|c|}
\hline \multicolumn{2}{|c|}{ Variable } & $N(158)$ & Mean stress score $\&$ SD & Test of sig. & $P$ value \\
\hline \multirow{3}{*}{ Age } & $20-30$ & 86 & $17.15 \pm 10.17$ & \multirow{3}{*}{$F=2.926$} & \multirow{3}{*}{0.057} \\
\hline & $31-40$ & 59 & $20.88 \pm 0.54$ & & \\
\hline & $41-50$ & 13 & $21.54 \pm 4.63$ & & \\
\hline \multirow{2}{*}{ Gender } & Female & 144 & $19.73 \pm 9.74$ & \multirow{2}{*}{$\mathrm{t}=3.390^{*}$} & \multirow{2}{*}{$<0.001$} \\
\hline & Male & 14 & $10.43 \pm 10.44$ & & \\
\hline \multirow{2}{*}{ Education level } & Secondary Education & 62 & $14.29 \pm 8.73$ & \multirow{2}{*}{$\mathrm{t}=4.937^{*}$} & \multirow{2}{*}{$<.001$} \\
\hline & High education & 96 & $21.89 \pm 9.88$ & & \\
\hline \multirow{2}{*}{ Residence } & Rural & 141 & $18.85 \pm 10.21$ & \multirow{2}{*}{$\mathrm{t}=0.85$} & \multirow{2}{*}{$>0.05$} \\
\hline & Urban & 17 & $19.35 \pm 9.60$ & & \\
\hline \multirow{3}{*}{ Smoking } & smoker & 2 & $7.00 \pm .000$ & \multirow{3}{*}{$\mathrm{F}=2.715$} & \multirow{3}{*}{0.69} \\
\hline & Non-smoker & 151 & $19.29 \pm 10.09$ & & \\
\hline & Ex-smoker & 5 & $12.00 \pm 8.22$ & & \\
\hline \multirow{2}{*}{ Type of work } & Permanent & 142 & $19.15 \pm 10.31$ & \multirow{2}{*}{$t=0.924$} & \multirow{2}{*}{0.357} \\
\hline & Temporary & 16 & $16.69 \pm 8.27$ & & \\
\hline \multirow{3}{*}{ Department } & ICU & 47 & $25.06 \pm 10.32$ & \multirow{3}{*}{$\mathrm{F}=0.283^{*}$} & \multirow{3}{*}{$<0.001$} \\
\hline & Medical & 58 & $12.26 \pm 8.64$ & & \\
\hline & Surgical & 53 & $20.72 \pm 6.82$ & & \\
\hline \multirow{3}{*}{ Job satisfaction } & Satisfied & 15 & $16.3 \pm 3.3$ & \multirow{3}{*}{$\mathrm{F}=4.4^{*}$} & \multirow{3}{*}{$<0.05$} \\
\hline & Average & 40 & $18.8 \pm 1.1$ & & \\
\hline & Dissatisfied & 103 & $20.6 \pm 1.9$ & & \\
\hline
\end{tabular}

A Significant association was found between Gender, educational level, Department, Job satisfaction on one side and stress and burnout score on the other side. But no significant association exist between age, residence, smoking and the score $(\mathrm{P}>0.05)$.

Table 2: Correlation between stress and Burnout score and each of working hours and working years.

\begin{tabular}{|c|c|c|}
\hline \multicolumn{2}{|c|}{} & SUM of stress score \\
\hline \multirow{2}{*}{ Working hours/ week } & Pearson Correlation & $.235^{* *}$ \\
\cline { 2 - 3 } & Sig. (2-tailed) & 0.003 \\
\hline \multirow{2}{*}{ Working years } & Pearson Correlation & 0.045 \\
\cline { 2 - 3 } & Sig. (2-tailed) & 0.577 \\
\hline
\end{tabular}

A significant correlation was found between working hours and stress and burnout score. But no significant correlation existed between working years and the score.

Table 3: Relation between mean stress score \& Burnout prevention category.

\begin{tabular}{|c|c|c|c|c|c|}
\hline Burnout prevention category & $\mathbf{N}$ & Percent & Mean stress and burnout score \pm Std. Deviation & Anova test & P value \\
\hline Unable to cope with stress & 105 & 66.5 & $19.30 \pm 10.942$ & \\
\\
\hline Coping with stress to some extent & 48 & 30.4 & $19.15 \pm 7.941$ & \multirow{2}{*}{2.85} & \multirow{2}{*}{0.061} \\
\hline Coping well with stress & 5 & 3.2 & $8.40 \pm 4.930$ & & \\
\hline Total & 158 & 100 & $18.91 \pm 10.121$ & \\
\hline
\end{tabular}

In this study, about $67 \%$ percent of nurses are unable to cope with stress, with only 3.2 percent cope well with stress. Stress with high mean stress score for those who are unable to cope with stress but this relation was not significant $(\mathrm{P}>0.05)$. 


\section{Ergonomics International Journal}

Table 4: Logistic regression of burnout, Gender, Education, Working hours/W and Departments.

\begin{tabular}{|c|c|c|c|c|}
\hline \multirow{2}{*}{ Variable } & \multirow{2}{*}{ OR } & \multicolumn{2}{|c|}{ 95\% CI } & \multirow{2}{*}{ P value } \\
\cline { 3 - 4 } & & Lower & Upper & \\
\hline Sex & 0.332 & 0.059 & 1.883 & 0.213 \\
\hline Education & 0.176 & 0.07 & 0.442 & 0 \\
\hline Department & 1.435 & 0.63 & 3.268 & 0.39 \\
\hline Working hours/ week & 3.692 & 1.717 & 7.939 & 0.001 \\
\hline Job satisfaction & 1.27 & 0.66 & 0.556 & 2.9 \\
\hline
\end{tabular}

OR: odds ratio; CI: confidence interval; significant independent factors for burnout includes education level, and working hours/w

Logistic regression of burnout, Gender, Education, Working hours/W, and Departments. The only significant independent factors associated with burnout are education and working hours per week.

Table 5: Correlation between working hours/w, working years \& Burnout prevention category.

\begin{tabular}{|c|c|c|c|}
\hline \multicolumn{2}{|c|}{} & Working hours/w & Working years \\
\hline \multirow{2}{*}{ Burnout prevention score } & Pearson Correlation & -0.087 & $-.225^{* *}$ \\
\cline { 2 - 4 } & Sig. (2-tailed) & 0.277 & 0.004 \\
\hline
\end{tabular}

There is a significant correlation between a number of working years and ability to take preventive measures to cope with stress.

Table 6: Relation burnout prevention categories, sociodemographic and working factors.

\begin{tabular}{|c|c|c|c|c|c|c|c|c|c|c|}
\hline \multirow[t]{2}{*}{ Variable } & \multicolumn{2}{|c|}{$\begin{array}{c}\text { Coping Well With } \\
\text { Stress } \mathrm{N}=5\end{array}$} & \multicolumn{2}{|c|}{$\begin{array}{c}\text { Coping With Stress To Some } \\
\text { Extent } N=48\end{array}$} & \multicolumn{2}{|c|}{$\begin{array}{c}\text { Unable To Cope With } \\
\text { Stress } N=105\end{array}$} & \multicolumn{2}{|c|}{$\begin{array}{c}\text { Total }(\mathrm{N}= \\
158)\end{array}$} & \multirow[t]{2}{*}{$\mathrm{X} 2$} & \multirow[t]{2}{*}{$\mathbf{P}$} \\
\hline & $\mathbf{N}$. & $\%$ & $\mathbf{N}$. & $\%$ & N. & $\%$ & $\mathbf{N}$. & $\%$ & & \\
\hline \multicolumn{11}{|c|}{ Age } \\
\hline $20-30$ & 5 & 100 & 25 & 52.1 & 56 & 53.3 & 86 & 54.4 & 6.43 & 0.169 \\
\hline $31-40$ & 0 & 0 & 21 & 43.8 & 38 & 36.2 & 59 & 37.3 & & \\
\hline $41-50$ & 0 & 0 & 2 & 4.2 & 11 & 10.5 & 13 & 8.2 & & \\
\hline \multicolumn{11}{|c|}{ Sex } \\
\hline Male & 0 & 0 & 2 & 4.2 & 12 & 11.4 & 14 & 8.9 & 2.653 & 0.265 \\
\hline Female & 5 & 100 & 46 & 95.8 & 93 & 88.6 & 144 & 91.1 & & \\
\hline \multicolumn{11}{|c|}{ Residence } \\
\hline Rural & 5 & 100 & 42 & 87.5 & 94 & 89.5 & 141 & 89.2 & 0.763 & 0.683 \\
\hline Urban & 0 & 0 & 6 & 12.5 & 11 & 10.5 & 17 & 10.8 & & \\
\hline \multicolumn{11}{|c|}{ Education } \\
\hline $\begin{array}{l}\text { Secondary } \\
\text { Education }\end{array}$ & 2 & 40 & 19 & 39.6 & 41 & 39 & 62 & 39.2 & 0.005 & $>.997$ \\
\hline High education & 3 & 60 & 29 & 60.4 & 64 & 61 & 96 & 60.8 & & \\
\hline \multicolumn{11}{|c|}{ Department } \\
\hline ICU & 2 & 40 & 17 & 35.4 & 28 & 26.7 & 47 & 29.7 & 8.66 & 0.07 \\
\hline Medical & 3 & 60 & 21 & 43.8 & 34 & 32.4 & 58 & 36.7 & & \\
\hline Surgical & 0 & 0 & 10 & 20.8 & 43 & 41 & 53 & 33.5 & & \\
\hline \multicolumn{11}{|c|}{ Type of work } \\
\hline Permanent & 5 & 100 & 43 & 89.6 & 94 & 89.5 & 142 & 89.9 & 0.58 & 0.748 \\
\hline Temporary & 0 & 0 & 5 & 10.4 & 11 & 10.5 & 16 & 10.1 & & \\
\hline
\end{tabular}

No significant association was detected between age, sex, residence, education, and department, type of work and burnout prevention categories of participant nurses. 


\section{Ergonomics International Journal}

\section{Discussion}

Burnout is a cumulative negative reaction to constant occupational stress resulting from misfit between workers and their designated jobs. As defined by Leiter MP, et al. \& Maslach C $[11,12]$ Burnout among health care workers, mainly medical staff, was becoming an occupational hazard, with its rate reaching between $25 \%$ and $75 \%$ in some clinical specialties [13].

This study investigates stress and burnout situation among nurses working in Menoufia University hospitals.

No significant association was found between age and mean stress score ( $P>0.05$, Table 1$)$, similar results obtained by Aslan $\mathrm{H}$, et al. [14]. While that of Labrague L [15] detected an association between age and stress score with high-stress score among younger age due to emotionally oriented responses in coping with stress than the older one. In addition, as age increased, knowledge and clinical experiences increased together with increased acquired preventive strategies and problemsolving ways in response to stress [16].

Female nurses have significant high mean stress score, this is in accordance with many studies and it can be explained by the additional effect of family-related stress which is found to be greater for females than males a finding that agree with that of Kamal A, et al. [17] who found that gender did significantly affect work-related stress during his study on concerning Prevalence and risk factors of work-related stress among residents at Ain Shams University Hospitals. His explanation was that responsibilities of career and families are likely to add a significant load on female's physical and mental health, and the load itself might be an additional source of workrelated stress an explanation that also, Mets that of work stress $[18,19]$.

In addition, the study of Korkmaz M, et al. [20] revealed that "female participants experience more stress-related problems than male participants; however, their reactions are lower than those given by the males".

Concerning the education level, those who were high education experienced significant high-stress score $(\mathrm{P}<0.05$, Table 1$)$ and this may be attributed to high mental stress, poor control of time, poor communication with administration. work related strain and risks to health are most likely to arise when high job demands are coupled with low decision latitude (that is, low personal control over work and limited opportunities to develop skills) [21].

El Dalatony MM, et al. Stress and Burnout among Nurses Working in Menoufia University Hospitals. Ergonomics Int J 2019, 3(3): 000207.
Another study of perceived stress revealed that "physicians and other health personnel especially those with advanced age and inadequate education are more likely to experience high-stress scores" [22].

In this work, no significant relation was detected between residence and mean stress score $(P>0.05$, Table 1), while the study of Schuler R, et al. [23] found that rural workers may be more tolerant and more willing to adapt and adjust to a situation. No significant relation was detected between type of nurse contract whether permanent or temporary and mean stress score $(P>0.05$, Table 1). Study of Yen Y, et al. [24] found that temporary nurses in the sample were generally younger, less experienced, unmarried, or married without children and they suffer from greater job stress and lower effective organizational and occupational commitments compared to their permanent counterparts. Temporary employees receive less compensation, fewer benefits, and little opportunity for advancement. Moreover, temporary employees are reported to have less participative decision making and are likely to have less job control $[25,26]$.

A significant finding of this study is that nurses working in critical care areas are experienced high stress and burnout scores $(\mathrm{P}<0.05$, table 1$)$ which may be explained by working environment in critical care area which is closed, noisy, hyperactive and highly technical and exposure to highly stressful and emotional situations, such as the relapse or death of a patient [27].

Many studies have examined occupational stress in nurses, especially in clinical settings. Results of those studies represent that stressors are many and varied $[16,28,29]$. Frequently occupational stressors in nurses include workload, caring of dead and dying, role ambiguity, conflict with physicians or other nurses, insufficient staff, and working overtime [30].

Nurses in different working areas experienced a different degree of work-related stress due to different workplaces with different tasks, working conditions, and stressful situations, for example, emotional suffering and death of a patient [31].

Also, a study of Mealer $M$, et al. [32] found that Intensive care unit (ICU) nurses are in general constantly exposed to work-related stresses resulting in the development of psychological disorders including posttraumatic stress disorder and burnout syndrome.

A significant association between job satisfaction category and mean stress score has been declared in Table $1 \quad(\mathrm{P}<0.05)$. There is an inverse relationship 


\section{Ergonomics International Journal}

between stress and job satisfaction, as stress goes up, job satisfaction falls [33].

No significant finding between working years and mean stress scores ( $p>0.05$, Table 2) and this could be explained by accommodation to the working situation. A finding that was supported by the study results of Ojekou G, et al. [34] who stated that level of stress was higher among the staff nurses who have worked for only between 0-3 years, most of them are never married with no family social support, they recorded a mean score of 46.0000. This can be associated with the fact that they are new in the institution of care, in a new and strange environment especially when expectations are not met, stress increases. As they get older in the establishment they acclimatize, adjust to the rules and regulations of the institution and experience less stress.

On the other hand, the significant association is found between the number of working hours/ week and stress and burnout score (Table 2). A similar finding was also detected by Aslam H, et al. [35] who stated that working long hours requires constantly caring for ill people, facing the death of people and knowing that their occupation carries enormous responsibility and that people's lives depend on them [36].

Study of Beşer N, et al. [22] revealed that those with more working years, working hours and working at units where more confrontation is experienced with patients' relatives such as emergency service may have feelings of incompetence.

As regard distribution of nurses regarding burnout prevention level (Table 3), 67\% percent of nurses are unable to cope with stress, $30 \%$ coping with stress to some extent, $3 \%$ cope well with stress, with observable decline in the stress score level and this inverse apparent relations between stress score and coping abilities seems to be logical unless other factors exist to modify the coping behavior. Study of Kawamura Y, et al. [36] detect a significant association between burnout and SOC score (sense of coherence scale which is a measure for stress coping abilities, with higher scores indicating higher stress coping ability).

People react to stress in different ways, some coping much better than others and suffering fewer of the harmful effects of stress, while others can find it not easy to keep a healthy balance among work and non-work life [37].

Logistic regression analysis showed that education and working hours/week are the important predictive factor for burnout after adjusting for stress factors (Table 4). Multifaceted approach directed towards the investigation of working conditions among nurses is strongly recommended including nature of work, responsibilities, support at work, Job satisfaction.

Social support from supervisors and colleagues has a negative association with work stress. Work empowerment also showed a strong and negative association with job tension and a positive association with work effectiveness. Psychological empowerment had a positive effect on job satisfaction and a negative influence on job strain. In the health care organization, work stress may contribute to absenteeism and turnover, both of which detract from the quality of care [27].

There is a significant association between working years and burnout prevention score (Table 5) and this again contributed to much more experience gained with working years and acclimatization which help adaptation to stressful working conditions. On the other hand, no significant association detected between working hours and stress prevention score.

No significant association was detected between the sociodemographic, type of work and burnout prevention score (Table 6).

\section{Conclusion}

- A comprehensive approach directed toward control of stress among nurses is required including the review of the working conditions, working environment, number of working hours, and Job satisfaction of nurses.

- Involvement of hospital administration to provide solutions to control stress among nurses include staff meeting, staff educational program, job rotation to ensure skill use, giving staff empowerment.

- Counseling of nurses with a high-stress score is required to alter their behavior and increased capabilities for coping with stress.

\section{References}

1. Centers for Disease Control and Prevention (CDC), National Institute for Occupational Safety and Health (NIOSH) (2016) Exposure to stress: occupational hazards in hospitals. Department of Health and Human Services (DHHS), Public Health Service, Publication No. 2008, Cincinnati, OH: USA 136: 1-13.

2. Bulik N (2006) Occupational stress and its consequences In healthcare professionals: the role of type $\mathrm{D}$ personality. International Journal of 
Occupational Medicine and Environmental Health 19(2): 113-122.

3. Elshaer N, Moustafa M, Aiad M, Ramadan M (2018) Job Stress and burnout syndrome among critical care healthcare Workers. Alexandria Journal of Medicine 54(3): 273-277.

4. El-Hadidi N, Abdel Hamied A, El-Bestar S (2017) Job burnout among employees in national bank of egypt at mansoura city. Egyptian Journal of Occupational Medicine 41(1): 143-155.

5. Embriaco N, Papazian L, Barnes N, Pochard F, Azoulay E (2007) Burnout syndrome among critical care healthcare workers. Curr Opin Crit Care 13(5): 482488.

6. Halder S, Mahato A (2013) Stress and psychological well-being status among health care professionals. International Journal of Occupational Safety and Health 3(1): 32-35.

7. Geuensa N, Braspenning $M$, Bogaertb P, Franck E (2015) Individual vulnerability to burnout in nurses: The role of Type D personality within different nursing specialty areas. Burnout Research 2: 80-86.

8. Koval Liliia (2016) Stress management among health care professionals: Psychological methods and coping techniques. Laurea University of Applied Sciences unit Degree Programme in Nursing Bachelor's Thesis, pp: $1-52$.

9. Job Satisfaction Survey (2007) Absolute Advantage-a workplace wellness magazine published. Wellness Council of America 3(5).

10. Stress and Burnout Questionnaire.

11. Leiter MP, Maslach C (2003) Areas of worklife: a structured approach to organizational predictors of job burnout. In: Perrewé P, Ganster DC, (Eds.), Research in occupational stress and well-being, Elsevier, Oxford, UK, pp: 91-134.

12. Maslach C (2003) Job burnout: new directions in research and intervention. Curr Dir Psychol Sci 12(5): 189-192.

13. Laschinger $H$, Wong $C$, Greco $P$ (2006) The impact of staff nurse empowerment on person-job fit and work engagement/burnout. Nurs Adm Q 30(4): 358-367.

\section{Ergonomics International Journal}

14. Aslan H, Akturk U (2018) Nursing education stress levels of nursing students and the associated factors. Annals of Medical Research 25(4): 660-666.

15. Labrague L (2013) Stress, stressors, and stress responses of student nurses in a government nursing school. Health Sci J 7(4): 424-435.

16. Parikh P, Taukari A, Bhattacharya (2004) Occupational stress and coping among nurses. Journal of Health Management 6(2): 115-127.

17. Kamal A, Sabbour S, Habeel I, Ghanem E (2015) Prevalence and risk factors of work-related stress among residents at Ain Shams University Hospitals. The Egyptian Journal of Community Medicine 33(3): 81-98.

18. Chan B, Lai G, Ko Y, Boey K (2000) Work stress among six professional groups: the Singapore experience. Social Science and Medicine 50(10): 1415-1432.

19. Narayan L, Menon S, Spector P (1999) Stress in the workplace: A comparison of gender and occupations. Journal of Organizational Behavior 20(1): 63-73.

20. Korkmaz M, Ceylan B (2012) Organizational stress management and applied analysis of effect of stress on work performance of Istanbul metropolitan municipality employees. Adiyaman University, Journal of Social Sciences 10: 313-344.

21. Michie S (2002) Causes and management of stress at work. Occup Environ Med 59(1): 67-72.

22. Beşer N, Çevik B (2018) Perceived Stress Levels of Physicians and Other Health Personnel Working in the 112 Emergency Service and Associated Factors. Nursing Studies and Practice International 1(1): 1005.

23. Schuler R (1973) Worker background and job satisfaction: comment. Industrial Relations and Labor Review 26(2): 851-853.

24. Yen Y, Ko J, Chang Y, Chen C (2007) Job stress and work attitudes between temporary and permanently employed nurses. Stress and Health 23(2): 111-120.

25. Parker S, Griffin M, Sprigg C, Wall T (2002) Effect of temporary contracts on perceived work characteristics and job strain: A longitudinal study. Personnel Psychology 55(3): 689-719. 


\section{Ergonomics International Journal}

26. Jalonen P, Virtanen M, Vahtera J, Elovainio M (2006) Predictors of sustained organizational commitment among nurses with temporary job contracts. Journal of Nursing Administration 36(5): 268-276.

27. Jennings BM (2008) Work stress and burnout among nurses: role of the work environment and working conditions. In: Chapter 26, Patient Safety and Quality: An Evidence-Based Handbook for Nurses, Agency for healthcare and quality (AHRQ), National Centre for Biotechnology Information, USA, 2: 137-158.

28. Evans L (2000) An exploration of district nurses perception of occupational stress. British journal of nursing 11(8): 576-585.

29. Mc vicar A (2003) Workplace stress in nursing: a literature review. Journal of Advance Nursing 44(6): 633-642.

30. Yeh MC, Huang HM (2007) Occupational stress among newly-graduated nurses: an exploratory study. Hung Kuang Journal 50: 1-12.

31. Gray $P$ (1999) Mental health in the workplace; tackling the effects of stress. Mental Health Foundation, London.

32. Mealer M, Jones J, Newman J, McFann KK, Rothbaum $\mathrm{B}$, et al. (2012) The presence of resilience is associated with a healthier psychological profile in ICU nurses: Results of a national survey. Int J Nurs Stud 49(3): 292-299.

33. Mathew M (2013) Effect of stress on job satisfaction among nurses in central kerala. OSR Journal of Business and Management (IOSR-JBM) 7(2): 47-51.

34. Ojekou G, Dorothy O (2015) Effect of work environment on level of work stress and burnout among nurses in a teaching hospital in Nigeria. Open Journal of Nursing 5: 948-955.

35. Aslam H, Mansoor N, Suleman Q (2013) Analysis of level of stress among doctors in public and private hospitals of Pakistan. International Journal of Learning \& Development 3(2): 109-135.

36. Kawamura Y, Takayashiki A, Ito M, Maeno T, Seo E, et al. (2018) Stress factors associated with burnout among attending physicians: A Cross-Sectional Study. J Clin Med Res 10(3): 226-232.

37. Meneze M (2005) The impact of stress on productivity at education training \& development practices. Sector Education and Training Authority (Master thesis, university of Pretoria, South Africa), pp: 1-140. 